\title{
Physical activity, energy balance and obesity
}

\author{
José Luís Griera' ${ }^{1}$ José María Manzanares ${ }^{2}$, Montserrat Barbany ${ }^{3}$, José Contreras ${ }^{1}$, \\ Pilar Amigó ${ }^{2}$ and Jordi Salas-Salvadó ${ }^{2, *}$ \\ 'Unit of Cardiovascular risk, Department of Internal Medicine, University Hospital, Sevilla, Spain: \\ ${ }^{2}$ Endocrinology, and Nutrition and Dietetics Units, Department of Internal Medicine, Hospital Universitari de Sant \\ Joan de Reus, Universitat Rovira i Virgili, 43201 Reus, Spain: ${ }^{3}$ Centre Català de la Nutrició, Institut d'Estudis \\ Catalans, Barcelona, Spain
}

\section{Submitted 22 November 2006: Accepted April 2007}

\begin{abstract}
Obesity appears when energy intake exceeds energy expenditure. The most important variable compound of energy expenditure is physical activity. The global epidemics of obesity seem closely related to reduced physical activity and sedentariness widely increasing nowadays. Once obesity has developed, caloric intake becomes similar to energy expenditure. To lose weight, besides decreasing energy intake, energy expenditure must be increased. The promotion of physical activity is difficult and so the results of treatment of obesity are discouraging for doctors, other health professionals and patients. Proactive efforts from patients and health providers with an intensive feedback between them may be extremely helpful. Nevertheless, more studies are needed to provide better approaches on the role of physical activity for the prevention and treatment of obesity and for long-term weight-loss maintenance.
\end{abstract}

Epidemiology, prevention and treatment of obesity cannot be fully understood without considering physical activity. Physical activity is defined as any bodily movement produced by skeletal muscle that results in energy expenditure beyond resting expenditure. Exercise is a subset of physical activity that is planned, structured, repetitive and purposeful in the sense that improvement or maintenance of physical fitness is the objective.

Interrelations between low physical activity and the epidemiology of obesity and its effects on health are now clear $^{1}$. So, prevention of obesity might be achieved by increasing physical activity. Increasing physical activity is a logical tool for any weight-loss programme and is effective $^{2}$. More controversies persist on weight maintenance, but there are data suggesting that those persons who exercise tend to maintain their weight better ${ }^{3}$.

\section{Effects of sedentary lifestyle on obesity epidemics}

There is evidence that low levels of physical activity may be contributing to the increasing incidence of obesity. In several studies, baseline measures of physical activity were inversely related to body mass index (BMI). A low level of physical activity predicted high weight gain, and decreases in physical activity over time were associated with greater weight gain ${ }^{4}$. Physical activity can be divided into leisure-time physical activity (LTPA) and activity performed in daily living, or lifestyle physical activity (LSPA $)^{5}$. LTPA can be divided into exercise, sport, and household and other daily chores. Transportation to and from work is referred to as commuting physical activity. Video games, home computers and watching television with remote control devices now compete for LTPA. At the same time, jobs are more comfortable and sedentary ${ }^{6}$, and less physical activity is required for transportation ${ }^{7}$. The environment is a critical component for sedentariness. Industrialisation, urbanisation and improving income are each associated with car use, lifts, automatic washing machines and microwave ovens. While each may reduce physical activity only slightly, together they can have an important impact on total energy expenditure (TEE) $)^{4}$.

\section{Role of physical activity on energy balance}

The human body consumes energy in the form of resting energy expenditure (REE), thermal effect of food (TEF) and energy expenditure resulting from physical activity. TEF and REE are relatively constant and account for $70-80 \%$ of the $\mathrm{TEE}^{8}$. In contrast, the contribution of physical activity is highly variable between individuals and therefore may provide the opportunity to increase energy expenditure. REE serves as a reference value when the energy expenditure produced by different 
activities is measured. A light physical activity like reading and driving can be equal to REE $\times 1.5$. Other activities can be estimated in the same way (Table 1$)^{9}$. There are tables depicting the caloric expenditure produced by different activities, which show the energy expenditure to carry one's own weight around increases it. For instance, playing tennis induces an expenditure of $165 \mathrm{kcal}$ in $30 \mathrm{~min}$ for a person of $110 \mathrm{lb}$, but 312 if he or she weights $210 \mathrm{lb}^{10}$. As a person loses weight, for a given amount of time exercising, doing the same activity at the same intensity, fewer calories are lost. So, to maintain the same level of energy expenditure, more physical activity is required $^{11}$.

\section{Physical activity effects on obesity: benefits and risks}

Increasing physical activity alone without a meal plan is hardly effective in treating obesity ${ }^{2,12}$, but exercise in combination with diet produces a greater weight loss $(1.9 \mathrm{~kg})$ than diet alone $\mathrm{e}^{2,12,13}$; and it has many benefits for health ${ }^{14}$. For example, there have been observed improvements in prevention of type 2 diabetes mellitus ${ }^{15}$, lower levels of blood pressure, lipids and glycemia ${ }^{16-18}$, reduction in cardiovascular disease ${ }^{19}$, particularly heart disease, and in mortality ${ }^{20}$. Improvements in biliary disease, respiratory capacity, cancer, and in psychological parameters such as anxiety, depression and stress have also been reported ${ }^{21}$.

The most common risk of physical activity in adults is musculoskeletal injury. Risk of injury increases with obesity, volume of exercise and participation in vigorous exercise such as competitive sports, whereas higher fitness, supervision, stretching exercises, protective equipment such as bike helmets, and well-designed environments protect against injury. Vigorous physical activity acutely increases the risk of sudden cardiac death and myocardial infarction among individuals with both diagnosed and occult heart disease. The relative risk of both exercise-related myocardial infarction and sudden death is greatest in individuals who are infrequently physically active ${ }^{19}$.

\section{How much physical activity and how often}

Earlier guidelines advocating vigorous exercise for at least 20 min three times per week have been changed by a recommendation of 30 min of moderate-intensity physical activity on most days of the week ${ }^{14,22}$ to achieve a general health improvement. But to reach and maintain a weight loss, at least $150 \mathrm{~min}$ of moderate activity each week or $200-300 \mathrm{~min}^{23}$ or $60 \mathrm{~min}$ of daily moderate activity ${ }^{24}$ have been advocated. Recently, the International Association for the Study of Obesity gave two separate recommendations: To prevent the transition of overweight to obesity at least of $45-60 \mathrm{minday}^{-1}$ of moderate activity are needed, but to prevent weight regain 60-90 min day ${ }^{-1}$ of moderate activity are required in formerly obese individuals ${ }^{25}$. Lesser amounts of vigorous intensity activity are effective as well. For children, even more activity time is recommended (Table 2$)^{26}$.

Changes in activities that people engage in routinely are usually easier to make and sustain than the more substantial changes involved in adding a structured exercise programme such as jogging. Such programmes should start slowly. First, walking, then walking faster and then running or bicycling, aerobic dancing or swimming, $30 \mathrm{~min}, 5$ days a week ( $\left.150 \mathrm{~min} \mathrm{week}^{-1}\right)$. If the patient is capable of following that rhythm and shows a reasonable attitude and reaches that level with success, the doctor will consider the possibility of increasing the prescription to $60 \mathrm{~min}$ of physical training 5 days a week $(300 \mathrm{~min}$ week $^{-1}$ ). Each step may last for some weeks ${ }^{26}$. A pyramid of physical activities for adults has been proposed by the Spanish Society for the Study of Obesity (Fig. 1) ${ }^{27}$.

A long-term approach in order to change sedentary habits must be prepared, with an individual programme for each patient based on aerobic repetitive exercises. The limit for the individual session must not exceed $70-80 \%$ of the maximum heart rate corresponding to each

Table 1 Approximate energy expenditure for activity levels

\begin{tabular}{|c|c|c|}
\hline Activity & $\begin{array}{l}\text { Energy as } \\
\text { REE multiple }\end{array}$ & $\mathrm{kcal} \mathrm{min}{ }^{-1}$ \\
\hline \multicolumn{3}{|l|}{ Rest } \\
\hline Sleep, lying down & REE $\times 1.0$ & $1-1.2$ \\
\hline Very light & & \\
\hline Sitting and standing, painting, driving, laboratory work, ironing, sewing & $\mathrm{REE} \times 1.5$ & Until 2.5 \\
\hline Light & & \\
\hline $\begin{array}{l}\text { Walking about } 4-5 \mathrm{~km} \mathrm{~h}^{-1} \text {, working in the garage, carpentry, playing golf, sailing, playing ping-pong } \\
\text { Moderate }\end{array}$ & REE $\times 2.5$ & $2.5-4.9$ \\
\hline Walking 5.6-6.4 $\mathrm{km} \mathrm{h}^{-1}$, working with hoe, carrying a load, riding a bicycle, skating and dancing & REE $\times 5.0$ & $5.0-7.4$ \\
\hline Walking with a load uphill, cutting down trees, manual excavation, playing football or basketball & REE $\times 7.0$ & $7.5-12.0$ \\
\hline
\end{tabular}

REE - resting energy expenditure.

Source: Food and Nutrition Board, National Research Council ${ }^{9}$. 
Table 2 Different recommendations for doing physical activity

\begin{tabular}{|c|c|c|c|c|}
\hline Organisation/agency & $\begin{array}{l}\text { Year of the } \\
\text { recommendation }\end{array}$ & $\begin{array}{l}\text { Minimum length of } \\
\text { recommended } \\
\text { physical activity }\end{array}$ & $\begin{array}{l}\text { Minimum } \\
\text { recommended } \\
\text { intensity }\end{array}$ & Expected beneficial results \\
\hline $\begin{array}{l}\text { Center for Disease Control and } \\
\text { Prevention and American College of } \\
\text { Sport Medicine }\end{array}$ & 1995 & $\begin{array}{l}30 \text { min most days of } \\
\text { the week }\end{array}$ & Moderate & General health improvement \\
\hline $\begin{array}{l}\text { Surgeon General's Report on Physical } \\
\text { Activity and Health }\end{array}$ & 1996 & $\begin{array}{l}30 \text { min most days of } \\
\text { the week }\end{array}$ & Moderate & General health improvement \\
\hline American College of Sports Medicine ${ }^{23}$ & 2001 & $\begin{array}{l}150 \text { min week }^{-1} \\
200 / 300 \text { min week }^{-1}\end{array}$ & $\begin{array}{l}\text { Moderate } \\
\text { Moderate }\end{array}$ & $\begin{array}{l}\text { General health improvement } \\
\text { Long-term maintenance of weight } \\
\text { loss }\end{array}$ \\
\hline Institute of Medicine ${ }^{24}$ & 2002 & 60 min day $^{-1}$ & Moderate & $\begin{array}{l}\text { Avoid putting on weight and add } \\
\text { other benefits for health } \\
\text { independently of weight }\end{array}$ \\
\hline $\begin{array}{l}\text { International Association for the Study of } \\
\text { Obesity }\end{array}$ & 2003 & $\begin{array}{l}45-60 \min _{\text {day }}-1 \\
60-90 \text { min day }^{-1}\end{array}$ & $\begin{array}{l}\text { Moderate } \\
\text { Moderate }\end{array}$ & $\begin{array}{l}\text { Prevent transition to overweight or } \\
\text { obesity, avoid weight regain }\end{array}$ \\
\hline
\end{tabular}

Modified from Jakicic $^{26}$.

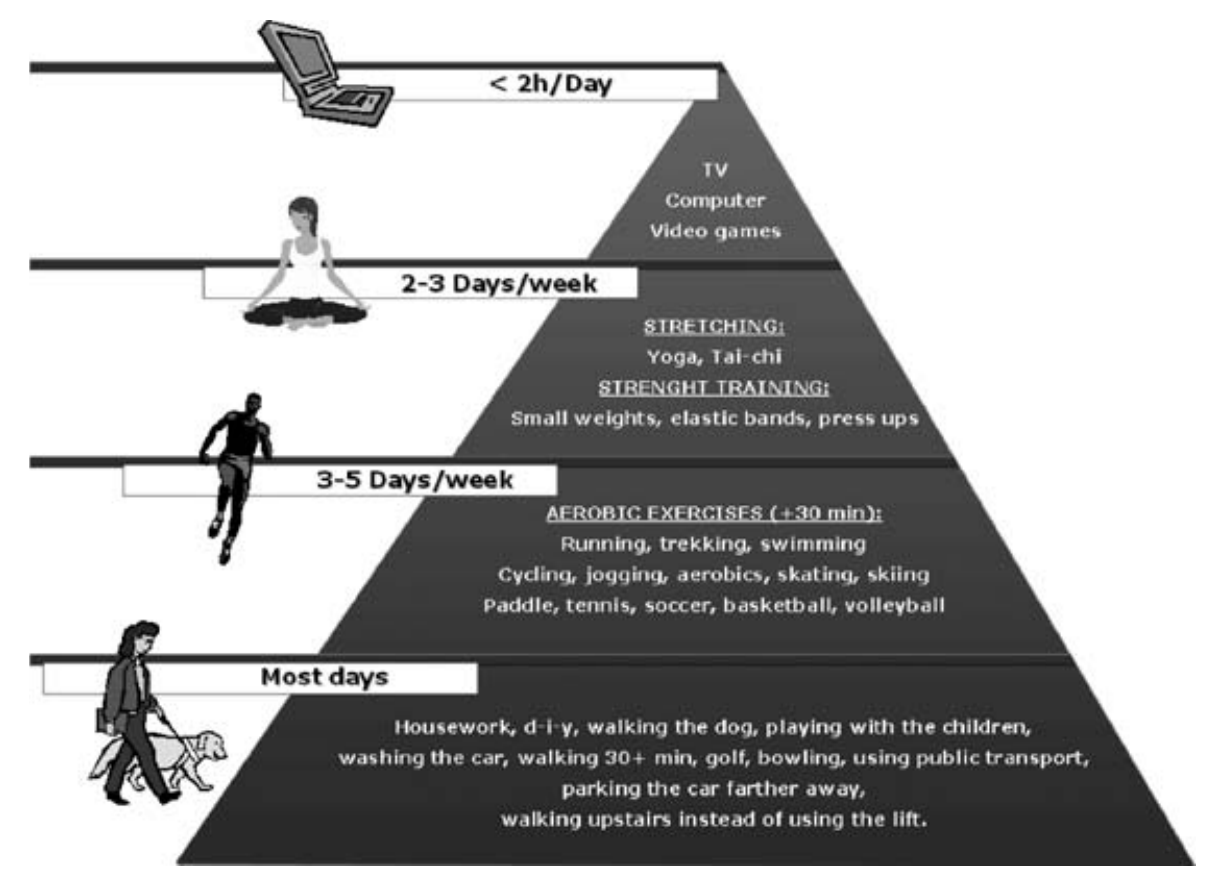

Fig. 1 Physical activity pyramid proposal for adults ${ }^{27}$

individual according to his age (recommended maximum heart rate: 220 - patient age). Stretching, warm-up and cool-down exercises at the beginning and the end of sessions are essential ${ }^{27}$.

Resistance exercises are also recommended 2-3 days per week. They consist of 8-10 different exercises, using the main muscle groups, with 10-15 repetitions for each type of programmed exercise. Increasing muscle mass has two results: First, increasing lean-mass that has more thermogenic activity may prevent weight regain. Second, increasing muscle strength can ameliorate usual life tasks, which is very important for elderly people ${ }^{27}$.

Physical activity can be assessed by different techniques: questionnaires, log books, diaries and pedometers. Pedometers are cheap devices, placed in the inner part of one of the legs at the waistline and registers the regular pace over the chosen period of time. The objective is to reach about 10000 paces per day. This figure is associated with an improvement in the health of the obese patient ${ }^{28}$. Sedentary people do not exceed 6000-7000 paces per day. The objective would be to increase the daily rate by 3000 paces. It is often difficult to motivate the patient to continue with such physical activity in order to reach the required aim and to maintain that routine in the long term $^{29}$.

\section{Individualisation of physical activity prescription}

Physical activity will be individualised according to individual ability and to the possible risk/benefit cost. 


\section{Patient attitude towards physical activity}

This factor will, on many occasions, lead to a failure of treatment. In order of frequency lack of motivation (85\%), too much work, lack of time, tiredness, laziness, all other kinds of inconveniences or lack of health (5\%) are the main complaints of patients. Few people claim lack of health (less than 5\%) in comparison with those who claim lack of motivation (more than $85 \%)^{12}$. Some patients wait for a 'miracle cure'. They are not interested in changing physical or dietetic habits or perhaps are looking for a definitive weight reduction in a short time. This type of patient has visited countless doctors previously. Jakicic ${ }^{26}$ proposes a kind of survey or an evaluation method of this predisposition step to behaviour change towards physical training, as shown in Table 3. According to the predisposition step where the patient is located, we shall project a different type of activity, and this will also influence the success rate. Setting up a programme of physical training always finds obstacles such as: 'I do not have time' and/or 'it is monotonous and boring'. To combat this, the professional must try to introduce an intermittent physical training programme or to incorporate some modifications in the patient style of life in order to increase the energy costs $^{24}$. Different routine activities may be useful for that purpose: walking up the stairs instead of taking the lift, parking the car farther away from the office and walking the rest of the way and so on can contribute to raise the caloric expense without changing the daily routine too much, thus increasing physical activity in those patients unwilling to start a programmed exercise plan. A guideline for intermittent activity would be to spread the programmed time for routine physical activity into several sessions or working periods through the day ${ }^{30}$. Adapting the activities to the family and social environment will increase the adherence to the programme. Other useful reinforcing techniques are group therapies, mailing, telephone and Internet contacts.

\section{Patients with osteoarthritis}

This is an especially difficult group. But with a slight weight loss, locomotive functional ability may improve. This will also improve the amount of physical activity, which, at the same time, will increase the weight loss and in this way shall break the tendency to gain weight. Lowimpact exercises (walking, cycling and swimming) cause less stress on bones and joints, whereas high-impact exercises (running and aerobic dancing) cause repeated impact on the knees, ankles and feet. Studies indicate that the intensity and nature of impact of physical activity are the two most important factors in determining the frequency of injuries.

\section{Patients with cardiac disease}

In these patients, physical activity will be programmed according to the grade of his/her disease. This must always be individualised and supervised by qualified staff. The American College of Sport Medicine ${ }^{12}$ has established practical categories to classify patients in relation to potential risks of any physical activity programme.

1. Patients with low risk: asymptomatic from a cardiovascular, pulmonary or metabolic disease viewpoint. Not more than one risk factor (the American Heart Association includes children and adolescents here).

2. Patients with moderate risk: men older than 45 years, women older than 55 years; at least two cardiovascular risk factors.

Table 3 Method of evaluating the predisposition to a change in the behaviour towards physical activity

Instructions for the patient:

Please read the following affirmations and select the one that with best accuracy reflects your real level of participation in a physical activity.

1. At the moment I do not want to do any physical activity and I am not considering starting a physical training programme.

2. At the moment I do not want to do any physical activity although I am considering starting a physical training programme.

3. At the moment I do not want to do any physical activity although I am making the arrangements to start a physical training programme in the new future.

4. At the moment I do physical activity. Nevertheless, I do it less than 150 min a week.

5. At the moment I do physical activity for at least $150 \mathrm{~min}$ a week, although I have so far spent less than 6 months on it.

6. At the moment I do physical activity for at least $150 \mathrm{~min}$ a week and I have spent more than 6 months on it.

The doctor classifies the patient in one of these predisposition phases considering the behaviour towards physical activity using the following categories:

Selected patient class Classification of predisposition phases considering the behaviour towards physical activity

\begin{tabular}{ll}
\hline Class 1 & Precontemplation phase \\
Class 2 & Contemplation phase \\
Class 3 & Preparation phase \\
Class 4 & Transition of preparation phase to action phase \\
Class 5 & Action phase \\
Class 6 & Maintenance phase
\end{tabular}

Physical activity is defined as a voluntary activity of intensity similar to one quick walk. Modified from Jakicic ${ }^{26}$. 
Table 4 Risk classification for physical training. Class A: apparently healthy individuals

This classification includes:

1. Children, adolescents, men $<45$ years and women $<55$ years who have no symptoms or known presence of heart disease or major coronary risk factors.

2. Men $\geq 45$ years and women $\geq 55$ years who have no symptoms or known presence of heart disease and with $<2$ major cardiovascular risk factors.

3. Men $\geq 45$ years and women $\geq 55$ years who have no symptoms or known presence of heart disease and with $\geq 2$ major cardiovascular risk factors.

Activity guidelines: no restrictions other than basic guidelines.

Supervision required: none*.

ECG and blood pressure monitoring: not required.

ECG - electrocardiography.

${ }^{*}$ It is suggested that people classified as Class A-2 and, particularly, Class A-3 undergo a medical examination and possibly a medically supervised exercise test before engaging in vigorous physical training.

Source: Fletcher et al. ${ }^{31}$.

3. Patients with high risk: signs/ symptoms of known cardiovascular, pulmonary or metabolic disease.

A statement by the American Heart Association (AHA) grades cardiovascular risk according to different criteria such as age of the patient, presence or absence of a known pathology and associated comorbidities. Some apparently healthy individuals may be prone to cardiological problems when they begin an exercise programme (class A, Table 4). People with known cardiac disease are graded in classes $\mathrm{B}, \mathrm{C}$ and $\mathrm{D}$ according to low, moderate or high risk when exercising. This statement provides standards and guidelines for the testing and training of all individuals. Followed carefully, it will allow the impact of physical training to improve their health without increasing the risk of a cardiac event ${ }^{31}$.

\section{Ageing}

Physical activity is particularly beneficial for elderly people. Besides the same effects cited before, quality of life and muscle strength are improved. Thus, it is important to recommend activities that require low-level energy expenditure, particularly during the first few weeks of the programme, and to prescribe mild increases at any time when progression of activity is made. In these instances, however, participants are encouraged to increase the frequency of exercise (for shorter duration), even to perhaps three or four times per day. They may require longer warm-up and cool-down periods, perhaps 10-15 min, and gradually taper exercise ${ }^{31,32}$.

\section{Summary}

1. A low level of physical activity is related to weight gain, and decreases in physical activity over time were associated with greater weight gain. Physical activity may provide an opportunity to increase energy expenditure.

2. Increasing physical activity alone without a meal plan is not very effective in treating obesity, but exercise in combination with diet produces a greater weight loss than diet alone, and it has many benefits to health.

3. A physical training programme should be developed according to the individual characteristics of the patient, in relation to his/her general health state, age, attitude and capacity to carry it out.

4. It will be essential to consider the 'invaluable collaboration' of the person and we shall have to encourage and stimulate him not to lose motivation in the development of the programme, and so it will be essential to explain the potential benefits he gains from doing it properly.

\section{Acknowledgements}

Sources of funding: This study was funded in part by the Instituto de Salud Carlos III (Thematic Network G03/ 140 and RD06/0045, and PI051839), Spain.

Conflict of interest declaration: No authors have any conflict of interest.

Authorship responsibilities: All the authors have participated in writing the manuscript.

\section{References}

1 DiPietro L. Physical activity, body weight and adiposity: an epidemiologic perspective. Exercise and Sport Sciences Reviews 1995; 23: 275-303.

2 Garrow J, Summerbell C. Meta-analysis: effects of exercise, with or without dieting, on body composition of overweight subjects. European Journal of Clinical Nutrition 1995; 49: 1-10.

3 Wing RR. Physical activity in the treatment of the adulthood overweight and obesity: current evidence and research issues. Medicine and Science in Sports and Exercise 1999; 31: $5547-52$.

4 Levine J, Peters J, Saris W, Hill J. Impact of physical activity on the emerging crisis of obesity in Asia. Asia Pacific Journal of Clinical Nutrition 2002; 11(Suppl.): S710-13.

5 Levine JA, Eberhardt NL, Jensen MD. Role of nonexercise activity thermogenesis in resistance to fat gain in humans. Science 1999; 283: 212-14. 
6 Fogelholm M, Mannisto S, Vartiainen E, Pietinen P. Determinants of energy balance and overweight in Finland 1982 and 1992. International Journal of Obesity and Related Metabolic Disorders 1996; 20: 1097-104.

7 Hu PS, Young JR. Personal Transportation Survey. Washington: Department of Transport, 1995.

8 Johnson RK. Energy. In: Mahan LK, Escott-Stump S, eds. Krause's Food, Nutrition \& Diet Therapy. Philadelphia, PA: McGraw-Hill Inc, tenth edition, 1995; 20-32.

9 Food and Nutrition Board, National Research Council. NAS: Recommended Dietary Allowances, 10th edn. Washington, DC: National Academy Press, 1989: 27.

10 Gutin B, Kessler G. The High Energy Factor. New York: Random House, 1983.

11 Woo R, Garrow JS, Pi-Sunyer FX. Effect of exercise on spontaneous calorie intake in obesity. American Journal of Clinical Nutrition 2002; 36: 470-7.

12 Jakicic JM, Otto AD. Physical activity considerations for the treatment and prevention of obesity. American Journal of Clinical Nutrition 2005; 82(Suppl.): 226S-9S.

13 National Heart Lung and Blood Institute. Clinical guidelines on the identification, evaluation and treatment of overweight and obesity in adults. Obesity Research 1996; 6(Suppl. 2): 51S-210S.

14 US Department of Health and Human Services. Physical Activity and Health: a Report of the Surgeon General. Atlanta, GA: US Department of Health and Human Services, Centers for Disease Control and Prevention, National Center for Chronic Disease Prevention and Health Promotion, 1996.

15 Tuomilehto J, Lindstrom J, Eriksson JG, Valle TT, Hamalainen $\mathrm{H}$, Pirjo Ilanne-Parikka $\mathrm{P}$, et al. Prevention of type 2 diabetes mellitus by changes in lifestyle among subjects with impaired glucose tolerance. New England Journal of Medicine 2001; 344: 1343-50.

16 Fagard R. Physical activity in the prevention and treatment of hypertension in the obese. Medicine and Science in Sports and Exercise 1999; 31(Suppl.): S624-30.

17 Kraus WE, Houmard JA, Duscha BD, Knetzger KJ, Wharton MB, McCartney JS, et al. Effects of the amount and intensity of exercise on plasma lipoproteins. New England Journal of Medicine 2002; 347: 1483-92.

18 Kang J, Robertson RJ, Hagberg JM, Kelley DE, Goss FL, DaSilva SG, et al. Effect of exercise intensity on glucose and insulin metabolism in obese individuals and obese NIDDM patients. Diabetes Care 1996; 19: 341-9.

19 Thompson PD, Buchner D, Piña IL, Balady GJ, Williams MA, Marcus $\mathrm{BH}$, et al. Exercise and physical activity in the prevention and treatment of atherosclerotic cardiovascular disease: a statement from the Council on Clinical Cardiology (Subcommittee on Exercise, Rehabilitation, and Prevention) and the Council on Nutrition, Physical Activity, and Metabolism (Subcommittee on Physical Activity). Circulation 2003; 107: 3109-16.
20 Lee IM, Skerret PJ. Physical activity and all-cause mortality: what is the dose-response relation? Medicine and Science in Sports and Exercise 2001; 33(Suppl.): S459-71.

21 Warburton DER, Nicol CW, Bredin SSD. Health benefits of physical activity: the evidence. CMAJ 2006; 1746: 801-8.

22 Pate RR, Pratt M, Blair SN, Haskell WL, Macera CA, Bouchard C, et al. Physical activity and public health: a recommendation from the Centers for Disease Control and Prevention and the American College of Sports Medicine. JAMA 1995; 273: 402-7.

23 Jakicic JM, Clark K, Coleman E, Donnelly J, Foreyt J, Melanson E, et al. American College of Sports Medicine position stand; Appropriate intervention strategies for weight loss and prevention of weight regain for adults. Medicine and Science in Sports and Exercise 2001; 33(12): 2145-56.

24 Andersen RE, Wadden TA, Bartlett SJ, Zemel B, Verde TJ, Franckowiak SC. Effects of lifestyle activity vs structured aerobic exercise in obese women: a randomized trial. JAMA 1999; 281: 335-40.

25 Saris WH, Blair SN, van Baak MA, Eaton SB, Davies PSW, Di Pietro L, et al. How much physical activity is enough to prevent unhealthy weight gain? Outcome of the IASO 1st Stock Conference and consensus statement. Obesity Review 2003; 4: 101-14.

26 Jakicic JM. Exercise in the treatment of obesity. Endocrinology and Metabolism Clinics of North America 2003; 32(4): 967-80.

27 Rubio MA, Salas-Salvadó J, Barbany M, Moreno B, Aranceta J, Bellido D, et al. Consenso SEEDO 2007 para la evaluación del sobrepeso y la obesidad y el establecimiento de criterios de intervención terapéutica. Revista Española de Obesidad 2007; 5(3): 5-48.

28 Tudor-Locke CE, Bell RC, Myers AM, Harris SB, Lauzon N, Rodger NW. Pedometer-determined ambulatory activity in individuals with type 2 diabetes. Diabetes Research and Clinical Practice 2002; 553: 191-9.

29 Di Pietro L, Dziura J, Blair SN. Estimated change in physical activity level (PAL) and prediction of 5 -year weight change in men: the aerobic Center Longitudinal Study. International Journal of Obesity Related Metabolic Disorders 2004; 28: $1541-7$.

30 Jakicic JM, Wing RR, Butler BA, Robertson RJ. Prescribing exercise in multiple short bouts versus one continuous bout: effects of adherence, cardiorespiratory fitness, and weight loss in overweight women. International Journal of Obesity and Related Metabolic Disorders 1995; 19: 893-901.

31 Fletcher GF, Balady GJ, Amsterdam EA, Chaitman B, Eckel $\mathrm{R}$, Fleg J, et al. Exercise standards for testing and training: a statement for healthcare professionals from the American Heart Association. Circulation 2001; 104: 1694-740.

32 Stewart KJ. Physical activity and ageing. Annals of the New York Academy of Sciences 2005; 1055: 193-206. 